\title{
Glucagon-like peptide-1 release and satiety after a nutrient challenge in normal-weight and obese subjects
}

\author{
Tanja C. M. Adam* and Margriet S. Westerterp-Plantenga \\ Nutrition and Toxicology Research Institute Maastricht (NUTRIM), Department of Human Biology, Maastricht University, PO Box 616, \\ 6200 MD Maastricht, The Netherlands
}

(Received 5 May 2004 - Revised 24 August 2004 - Accepted 22 October 2004)

\begin{abstract}
The present study was conducted to assess whether glucagon-like peptide-1 (GLP-1) release and appetite after a breakfast with or without an additional galactose/guar gum stimulation is different in normal-weight compared with overweight/obese subjects. Twenty-eight overweight/obese (BMI $30 \cdot 3$ (SD 2.7 ) $\mathrm{kg} / \mathrm{m}^{2}$; age 44.3 (SD 9.7) years) and thirty normal-weight subjects (BMI 22.8 (SD 1.4), age 31.5 (SD 12.8) years) participated in a crossover study. Fasting and postprandial plasma GLP-1, insulin, glucose and free fatty acid concentrations were measured in response to either a galactose (50 g)/guar gum $(2.5 \mathrm{~g})$ load $(836 \mathrm{~kJ})$ and a standard breakfast $(1.9 \mathrm{MJ}$; GG), or water $(250 \mathrm{ml})$ and the standard breakfast (W) every 30 min relative to the ingestion for $120 \mathrm{~min}$. Appetite was assessed using $100 \mathrm{~mm}$ visual analogue scales. GLP-1 concentrations were significantly increased after GG at 30 and 60 min compared with W in both groups. Plasma GLP-1 concentrations in the W condition were higher in normal-weight than overweight/obese subjects $(P=0 \cdot 03)$. No difference was observed in the GG condition between groups. Satiety was increased in normal-weight compared with overweight/obese subjects in the GG condition at 30 $(P=0.02)$ and $60(P=0.04)$ min. We conclude that after a standard breakfast with water, GLP-1 release was lower in the overweight/obese than the normalweight subjects. However, postprandial GLP-1 release in overweight/obese subjects was no different from that of normal-weight subjects when galactose/ guar gum was added to the breakfast. The latter was not mirrored by subjective feelings of satiety. Disturbed perception of the physiological feedback of a satiety hormone rather than disturbed feedback itself might contribute to obesity.
\end{abstract}

Glucagon-like peptide 1: Obesity: Galactose: Satiety

Regulation of food intake is a complex process that involves physiological as well as social and psychological components. The way in which food is sensed and processed by the biological system generates and activates neural and humoral signals that control appetite. Glucagon-like peptide-1 (7-36) amide (GLP-1) is believed to be one of the gut peptides that are involved in satiety signalling, in addition to other signals that operate via gastric and small intestinal vagal afferent nerve fibres (Morley, 1990; Blundell et al. 1993; Näslund et al. 1998).

GLP-1 is a 30 amino-acid peptide hormone that is released from intestinal L-cells of the intestinal mucosa in response to nutrients and mixed meals (Kreymann et al. 1987; Elliott et al. 1993). It increases satiety and suppresses appetite in normal-weight subjects (Flint et al. 1998; Gutzwiller et al. 1999). GLP-1 release in response to nutrient sensing is known to stimulate insulin release in pancreatic $\beta$-cells (Tillil et al. 1988; Thorens et al. 1993; Flint et al. 1998; Gutzwiller et al. 1999). Findings on basal GLP-1 concentration and the effect of food intake on GLP-1 release and satiety in obese subjects are contradictory. Whereas one study reports the hypersecretion of truncated GLP-1 in obese subjects in response to a glucose load (Fukase et al. 1993), others find an attenuated release of GLP-1 in response to a meal (Ranganath et al. 1996). The peripheral administration of GLP-1 in obese subjects decreased hunger ratings and reduced energy intake (Näslund et al. 1999).
Although dietary fibre such as guar gum was found to effectively increase satiety and fullness ratings, and reduce hunger and desire to eat, in obese as well as normal-weight subjects in the short term (Lavin \& Read, 1995; Pasman et al. 1997), the evidence for its effect on weight loss is poor (Pittler \& Ernst, 2001). The effect of fibre on GLP-1 release seems unclear and has been found to be a matter of amount (Gee et al. 1996; Massimino et al. 1998); it has also been suggested to depend on structural food properties rather than the amount of fibre ingested (Juntunen et al. 2002). In an earlier study, we found that galactose in combination with guar gum before breakfast increased GLP-1 release in normal-weight subjects (Hughes et al. 2004). The aim of the present study was to investigate whether GLP-1 release would be increased postprandially in response to galactose with guar gum consumed before a standard breakfast (GG) in obese subjects compared with normal-weight subjects. Furthermore, we examined whether this was reflected in appetite ratings.

\section{Subjects and methods}

Subjects

Seventy subjects between the ages of 20 and 60 years were recruited by means of advertisements in local newspapers. Of

\footnotetext{
Abbreviations: AUC, area under the curve; FFA, free fatty acids; GG, galactose/guar gum and standard breakfast; GLP-1, glucagon-like peptide-1; W, water and standard breakfast.

* Corresponding author: Dr T. C. M. Adam, fax +31 43367 0976, email T.Adam@hb.unimaas.nl
} 
Table 1. Subject characteristics with their standard deviations expressed as means

\begin{tabular}{|c|c|c|c|c|c|}
\hline & \multicolumn{2}{|c|}{ Normal weight $(n 30)$} & \multicolumn{2}{|c|}{ Obese $(n 28)$} & \multirow[b]{2}{*}{$P$} \\
\hline & Mean & SD & Mean & SD & \\
\hline Age (years) & 31.58 & $12 \cdot 84$ & $44 \cdot 38$ & $9 \cdot 76$ & $0.0002^{*}$ \\
\hline Height (m) & 1.75 & 0.09 & $1 \cdot 71$ & 0.06 & 0.10 \\
\hline Weight (kg) & $69 \cdot 34$ & 7.09 & $89 \cdot 32$ & 8.92 & $0.0001^{*}$ \\
\hline BMI $\left(\mathrm{kg} / \mathrm{m}^{2}\right)$ & $22 \cdot 89$ & 1.49 & $30 \cdot 35$ & $2 \cdot 70$ & $0.0001^{*}$ \\
\hline $\begin{array}{c}\text { Percentage } \\
\text { body fat }\end{array}$ & $20 \cdot 49$ & $9 \cdot 02$ & $38 \cdot 15$ & $6 \cdot 13$ & $0.0001^{*}$ \\
\hline
\end{tabular}

* Significant difference between normal-weight $(n 30)$ and overweight/obese subjects ( $n$ 28; factorial ANOVA).

the fifty-eight subjects included, twenty-eight (nine male and nineteen female) were overweight/obese according to the WHO classification (WHO, 1998). Thirty subjects (fifteen male and fifteen female) were normal-weight controls (Table 1). Subjects were used to a laboratory environment since they frequently participated in experiments carried out at Maastricht University. Selection criteria included being in good health, not taking any medication, having no history of diabetes or chronic disease, and not participating in other ongoing or former studies that would influence the outcome of the present study.

The power calculation for the present study is based on previous results that are assumed as a scientifically important difference (Hughes et al. 2004) and has been calculated for a sensitivity of 0.90 and a two-sided significance level of 0.05 according to the standard equations (Bortz, 1993). Based on a difference between conditions of $8.6 \mathrm{pmol} / \mathrm{l}$ and an SD of 10 , we calculated twentysix subjects. If a Mann-Whitney $U$ test is applied, $n$ needs to be increased by $5 \%$, making twenty-eight subjects.

Informed written consent was obtained, and the study was approved by the Medical Ethics Committee of Maastricht University.

\section{Body weight and BMI}

For all subjects, body weight was measured on a digital balance (model 707; Seca, Hamburg, Germany; weighing accuracy $0.1 \mathrm{~kg}$ ), and height was measured using a wall-mounted stadiometer (model 220; Seca). BMI was calculated as body weight divided by height ${ }^{2}\left(\mathrm{~kg} / \mathrm{m}^{2}\right)$ (Table 1$)$.

\section{Body composition}

Total body water was measured using the ${ }^{2} \mathrm{H}\left({ }^{2} \mathrm{H}_{2} \mathrm{O}\right)$ dilution technique (Schoeller et al. 1980; van Marken Lichtenbelt et al. 1994). On the evening prior to the first test day, subjects drank an ${ }^{2} \mathrm{H}$ dilution $(70 \mathrm{~g}$ water with an enrichment of 5 atom\% excess ${ }^{2} \mathrm{H}$ ) after voiding. ${ }^{2} \mathrm{H}$ enrichment was measured in urine from the second voiding of the following morning. ${ }^{2} \mathrm{H}$ concentrations in the urine samples were measured using an isotope ratio mass spectrometer (Micromass; Optima, Manchester, UK). Total body water was determined by dividing the measured ${ }^{2} \mathrm{H}$ dilution space by 1.04 (Schoeller et al. 1980). Fat-free mass was calculated by dividing the total body water by the hydration factor 0.73 . By subtracting fat-free mass from body weight, fat mass was obtained. Body fat (\%) was calculated as fat mass expressed as percentage body weight (Table 1).

\section{Study protocol and meal}

Subjects came to the laboratory for two visits, separated by at least 1 week. The subjects were instructed to fast from 22.00 hours on the night prior to each visit. After arrival at 08.00 hours in the morning, an indwelling cannula (Baxter BV, Utrecht, The Netherlands) was inserted into an antecubital vein. After a baseline blood sample had been collected, subjects consumed a nutrient load $(836 \mathrm{~kJ})$ consisting of either $50 \mathrm{~g}$ galactose $(\mathrm{D}-(+)$-galactose; Fagron Farmaceuticals, Nieuwekerk a/d The Netherlands) and $2.5 \mathrm{~g}$ guar gum (Meyprofin, Kreuzlingen, Switzerland), dissolved in $250 \mathrm{ml}$ water, or $250 \mathrm{ml}$ water alone, in randomised order. After drinking the load, subjects had to eat a standard breakfast. Subjects were given $15 \mathrm{~min}$ to finish the meal. The breakfast $(1.9 \mathrm{MJ})$ had an energy density of $3.9 \mathrm{~kJ} / \mathrm{g}$ and consisted of two slices of brown bread $(100 \mathrm{~g})$, a baked egg $(85 \mathrm{~g})$ and $300 \mathrm{ml}$ skimmed milk. The distribution of energy was carbohydrate $48.8 \%$ energy, protein $28.5 \%$ energy and fat $22.6 \%$ energy. All the subjects reported that the breakfast was much bigger than they would usually eat.

Blood samples were taken every 30 min relative to ingestion for a total of $2 \mathrm{~h}$.

\section{Pre- and post-absorptive appetite profile}

To determine the appetite profile, satiety and desire to eat were rated on anchored $100 \mathrm{~mm}$ visual analogue scales before the meal (time 0), immediately after the meal (time 30) and every $30 \mathrm{~min}$ relative to the measurement after the meal for $2 \mathrm{~h}$. For the increase in satiety caused by the meal the change in satiety from the fasted rating at time 0 was calculated ( $\triangle$ satiety).

\section{Blood sample collection and processing}

Blood samples were taken to measure plasma GLP-1, insulin and glucose concentrations. Blood samples for GLP-1 were taken in iced syringes and mixed with EDTA and $40 \mu$ l Dipeptidyl Peptidase-IV inhibitor (Linco Research, St Charles, MO, USA) to prevent degradation. Blood samples for other blood parameters were mixed with EDTA to prevent clotting. Plasma was obtained by centrifugation for $10 \mathrm{~min}$ at $2800 \mathrm{~g}$ at $4^{\circ} \mathrm{C}$. Plasma was collected, frozen in liquid nitrogen and stored at $-20^{\circ} \mathrm{C}$ for analysis.

GLP-1 concentrations were measured using an ELISA kit (EGLP - 35K; Linco Research) for the non-radioactive quantification of biologically active forms of GLP. The assay has an intra-assay CV of $8 \%$ or less and an inter-assay CV of $12 \%$ or less. The sensitivity of the analysis is 2 pmol/l (Nathan et al. 1992).

Plasma glucose concentrations were determined using the hexokinase method (Glucose HK 125 kit; ABX diagnostics, Montpellier, France). The WAKO NEFA C-kit (Wako Chemicals, Neuss, Germany) was used to determine free fatty acid (FFA) concentrations. Insulin concentrations were measured using a radioimmunoassay method (Insulin RIA-100; Pharmacia, Uppsala, Sweden). 


\section{Statistical analysis}

For test of normality, data were tested with the Shapiro-Wilk test of normality.

A one-way repeated-measures ANOVA was carried out to determine the hormonal and appetite differences between GG and $\mathrm{W}$ per group. Hormonal parameters and area under the curve (AUC) were tested with a non-parametric Mann-Whitney $U$ test for differences between groups. AUC was calculated as incremental AUC over time ( $2 \mathrm{~h}$ ). Appetite differences for GG and $\mathrm{W}$ between obese and lean subjects were tested with factorial ANOVA. The relationship between age and blood parameters such as GLP-1, insulin, glucose and FFA was tested with a multiple regression analysis.

Results are presented as mean values and standard errors of the mean or medians and ranges as appropriate. Statistical procedures were performed by using Statview SE + Graphics (1988; Abacus Concepts, Berkeley, CA, USA).

For all statistical tests, the level of significance was set at $P<0 \cdot 05$.

\section{Results}

Differences between the GG and $W$ conditions

Fasting GLP-1 concentrations were no different between conditions in either the normal-weight or the obese group. In the normal-weight group, plasma GLP-1 was significantly increased in the GG condition compared with the $\mathrm{W}$ group at $30 \mathrm{~min}$ $\left(\mathrm{F}_{1,28}=30.09 ; P=0.0001\right)$ and $60 \mathrm{~min}\left(\mathrm{~F}_{1,28}=6.10 ; P=0.02\right)$ after ingestion of the load. Similarly, in the overweight/obese group, GLP-1 concentration in response to GG was higher at $30 \mathrm{~min} \quad\left(\mathrm{~F}_{1,27}=20.94 ; \quad P=0.0001\right), \quad 60 \mathrm{~min} \quad\left(\mathrm{~F}_{1,27}=4 \cdot 38\right.$; $P=0.045)$ and $90 \mathrm{~min}\left(\mathrm{~F}_{1,28}=6.39 ; P=0.017\right)$ compared with W (Fig. 1)

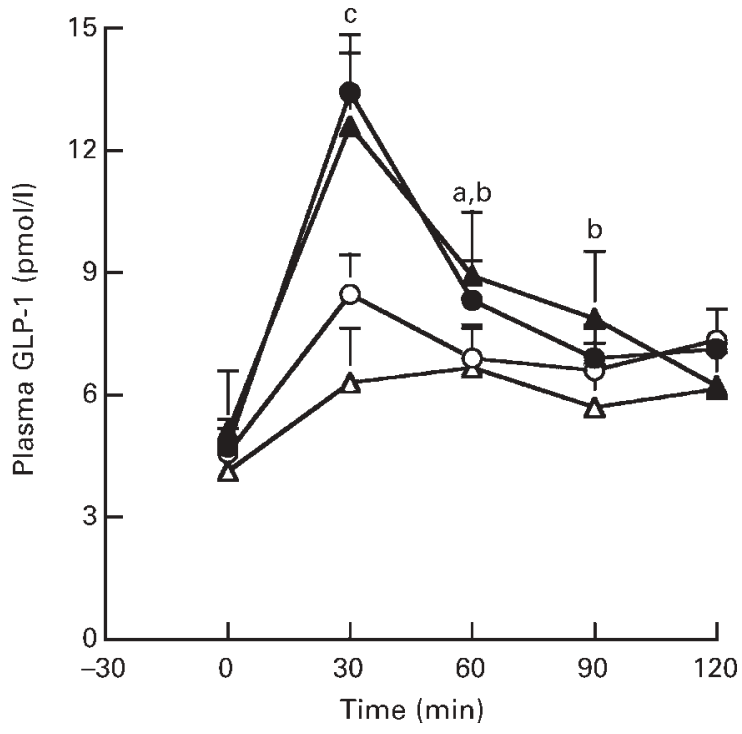

Fig. 1. Glucagon-like peptide-1 (GLP-1) plasma concentrations after the ingestion of galactose/guar gum and a standard breakfast (GG; $\bullet, \mathbf{\Delta}$ ) or water and a standard breakfast $(\mathrm{W} ; O, \triangle)$ in normal-weight $(O, \bullet)$ and obese $(\triangle, \boldsymbol{\Lambda})$ subjects. Values are means with their standard errors represented by vertical bars. ${ }^{\mathrm{a}} \mathrm{GG}$ normal weight different from $\mathrm{W}$ normal weight $(P<0.05)$. ${ }^{b} \mathrm{GG}$ obese different from $\mathrm{W}$ obese $(P<0.05)$. ${ }^{\mathrm{C}} \mathrm{GG}$ different from $\mathrm{W}$ in obese and normal-weight subjects $(P=0.0001)$.
In the lean as well as in the overweight/obese subjects, the change in insulin ( $\Delta$-plasma insulin) concentrations peaked at $60 \mathrm{~min}$ in the $\mathrm{W}$ condition. In lean subjects, $\Delta$-insulin concentrations were significantly higher in the $\mathrm{W}$ than in the GG

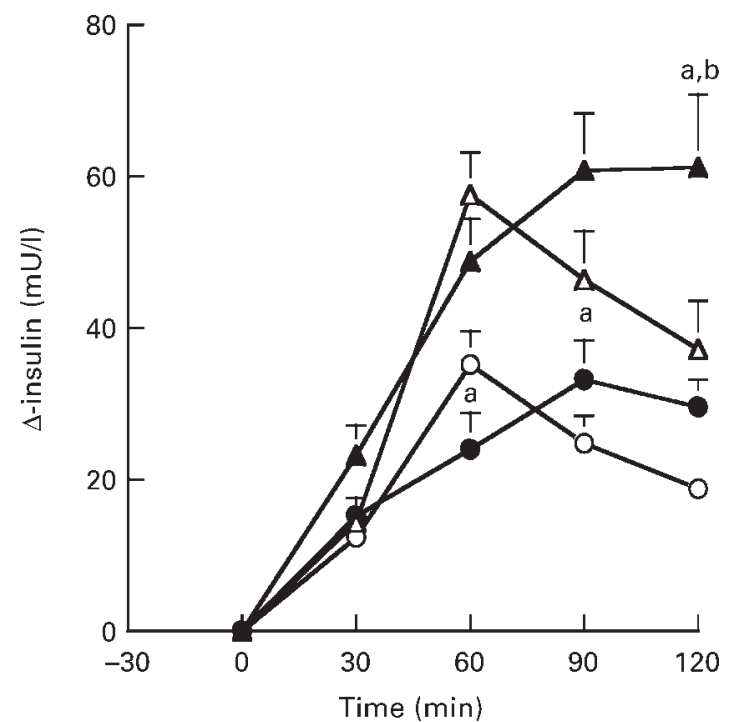

Fig. 2. $\Delta$-insulin plasma concentrations (change from fasted concentrations) after the ingestion of galactose/guar gum and a standard breakfast (GG;

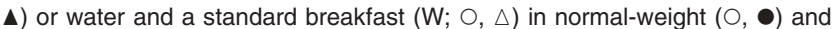
obese $(\triangle, \boldsymbol{\Delta})$ subjects. Values are means with their standard errors represented by veritical bars. ${ }^{a} G G$ normal weight different from $W$ normal weight $(P<0.05) .{ }^{b} \mathrm{GG}$ obese different from $\mathrm{W}$ obese $(P<0.05)$.

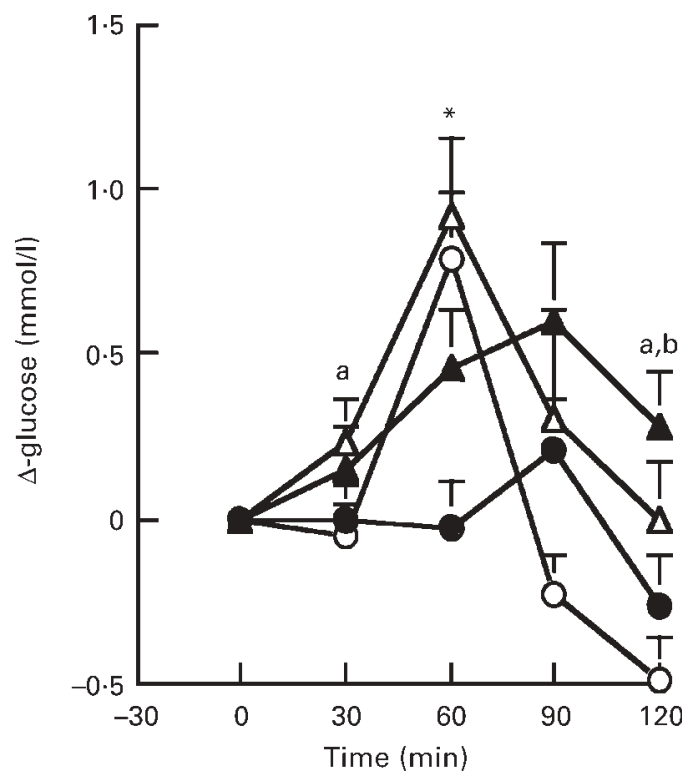

Fig. 3. $\Delta$-plasma glucose concentration (change from fasted concentrations) after the ingestion of galactose/guar gum and a standard breakfast (GG; $\boldsymbol{-}, \boldsymbol{\Delta})$ in normal-weight $(\bigcirc, \boldsymbol{\bullet})$ and obese $(\Delta, \mathbf{\Delta})$ subjects, compared with water and a standard breakfast $(\mathrm{W} ; O, \Delta)$ in normal-weight and obese subjects values are means with their standard errors represented by vertical bars. ${ }^{*} \mathrm{GG}$ normal weight different from $W$ normal weight $(P=0.003) .{ }^{a}$ Median difference of $\mathrm{W}$ in obese individuals is significantly different from $\mathrm{W}$ in normal-weight individuals at $30(P=0.04)$ and $120(P=0.05)$ min (Mann-Whitney $U$ test for two groups). ' $M$ Median difference of $G G$ in obese subjects is significantly different from $\mathrm{GG}$ in normal-weight subjects at $60(P=0.02)$ and $120(P=0.04) \min$ (Mann-Whitney $U$ test for two groups). 


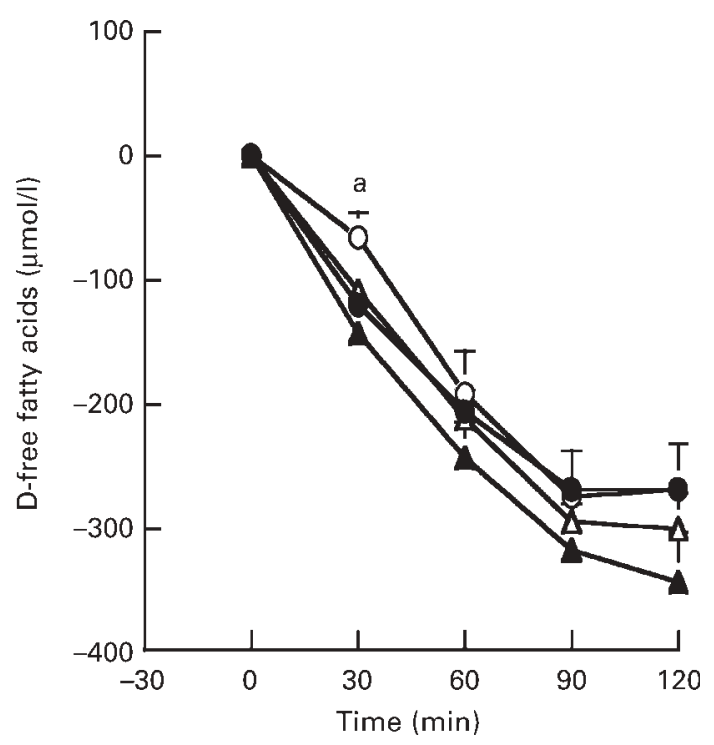

Fig. 4. $\Delta$-plasma free fatty acid concentration (change from fasted concentrations) after the ingestion of galactose/guar gum and a standard breakfast $(\mathrm{GG} ; \bullet, \mathbf{\Delta})$ in normal-weight $(\bigcirc, \bullet)$ and obese $(\triangle, \mathbf{\Delta})$ subjects, compared with water and a standard breakfast $(\mathrm{W} ; O, \Delta)$ in normal-weight and obese subjects. ${ }^{2}$ Median difference of $W$ in obese subjects is significantly different from $W$ in normal-weight subjects at $30 \mathrm{~min}(P=0.03$; Mann-Whitney $U$ test for two groups).

condition at $60 \mathrm{~min}\left(\mathrm{~F}_{1,25}=9.51 ; P<0.05\right)$ and were lower than the GG concentrations at $90\left(\mathrm{~F}_{1,24}=5.48 ; P<0.05\right)$ and 120 $\left(\mathrm{F}_{1,23}=15.87 ; P<0.05\right) \mathrm{min}$. In overweight/obese subjects, insulin concentrations were significantly different at $120 \mathrm{~min}$ $\left(\mathrm{F}_{1,17}=5.46 ; P<0.05\right)$ with lower plasma insulin concentrations in the $\mathrm{W}$ condition than the GG (Fig. 2).

In normal-weight subjects, plasma glucose concentrations (Fig. 3) were significantly higher after the ingestion of $\mathrm{W}$ compared with GG at $60 \mathrm{~min}\left(\mathrm{~F}_{1,28}=10 \cdot 3 ; P=0 \cdot 003\right)$. Glucose concentration in the overweight/obese group did not differ between GG and $\mathrm{W}$ at any point of measurement.

Plasma FFA concentration (Fig. 4) was higher in the normalweight group at $30 \mathrm{~min}\left(\mathrm{~F}_{1,25}=5.90 ; P=0.02\right)$ during the $\mathrm{W}$ compared with GG condition. There were no differences between $\mathrm{W}$ and GG at any other point of measurement. No differences were found in FFA concentration in the overweight/obese group when comparing $\mathrm{W}$ and $\mathrm{GG}$.

\section{Differences between normal-weight and obese subjects}

The overweight/obese subjects were on average older than the lean subjects. However, as tested, none of the blood parameters assessed was related to age.

Fasted GLP-1 concentrations did not differ between the groups in either the GG or the W condition. Normal-weight subjects had significantly higher GLP-1 concentrations after $\mathrm{W}$ at $30 \mathrm{~min}$ compared with the overweight/obese group $(P=0.02$; Table 2$)$. The AUC $(\mathrm{pmol} / \mathrm{l} \times \mathrm{h})$ for GLP-1 concentrations (Fig. 5(a)) after W was significantly different in the normal-weight group compared with the overweight/obese group $(6.42 \mathrm{pmol} / \mathrm{l} \times \mathrm{h}(4.52-9.13)$ compared with $4.2 \mathrm{pmol} / \mathrm{l} \times \mathrm{h}(2 \cdot 2-6 \cdot 8)) ; P=0.03)$. The AUC $(\mathrm{pmol} / \mathrm{l} \times \mathrm{h})$ for GLP-1 concentrations after GG was no different between groups (Fig. 5(b)). (a)
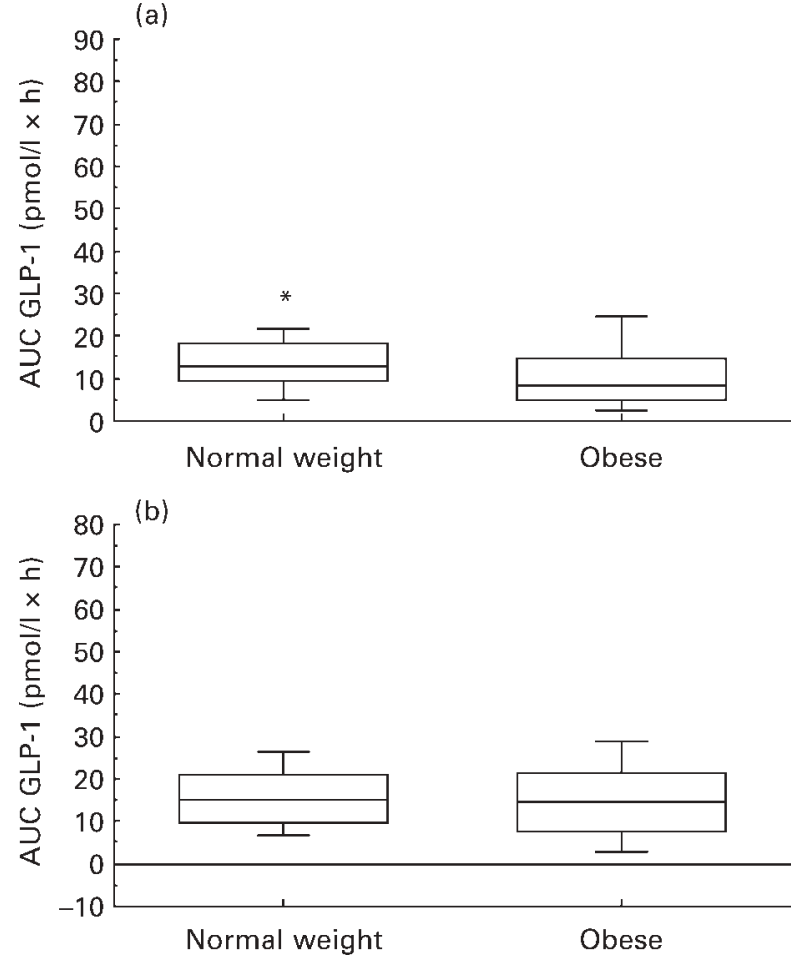

Fig. 5. Median (horizontal bar within box) of $A U C(p m o l / l \times h)$ for glucagonlike peptide-1 (GLP-1) concentrations in normal-weight and obese subjects after ingestion of W (a) or GG (b). The median difference for GLP-1 concentrations was significantly higher for normal-weight than obese subjects after ingesting water and a standard breakfast $(P=0.03$; Mann-Whitney $U$ test for two groups). This was not the case for ingestion of galactose/guar gum and a standard breakfast. AUC, area under the curve. Upper limit of box, 75th percentile; lower limit of box, 25th percentile; edge of upper limit, 90th percentile; edge of lower limit, 10th percentile.

Median fasted insulin concentrations were significantly different for GG as well as for $\mathrm{W}$ between lean and overweight/ obese subjects, with overweight/obese subjects having significantly higher fasted insulin concentrations in the $\mathrm{W}$ and the GG conditions ( $P=0.0001$; Table 2$)$.

Median differences between the overweight/obese and normalweight group for $\Delta$-glucose concentrations were significant at $30 \mathrm{~min}(P=0.04)$ and $120 \mathrm{~min}(P=0.05)$ in the $\mathrm{W}$ condition (Table 3). Values were different in the sense that overweight/ obese subjects had significantly higher glucose concentrations than normal-weight subjects after the ingestion of W. Median differences for $\Delta$-glucose concentrations were significant at $60 \mathrm{~min}$ $(P=0.02)$ and $120 \mathrm{~min}(P=0.04)$ between groups in the GG condition, with significantly higher glucose concentrations in the overweight/obese group than the normal-weight group (Table 3).

In the $\mathrm{W}$ condition, $\Delta$-FFA concentrations in the normal-weight group were significantly less decreased compared with the overweight/obese group at $30 \mathrm{~min}(P=0.03$; Table 3$)$. There were no differences between groups in $\Delta$-FFA concentrations in the GG condition.

Ratings of satiety (AUC) were related to GLP-1 concentrations (AUC) in the normal-weight group after ingesting GG $(r$ 0.20; $P=0.01)$, but not in the overweight/obese group $(r 0.07 ; P=0.74)$.

Ratings of satiety and desire to eat did not differ between groups in the $\mathrm{W}$ condition. After ingesting GG, the increase in 

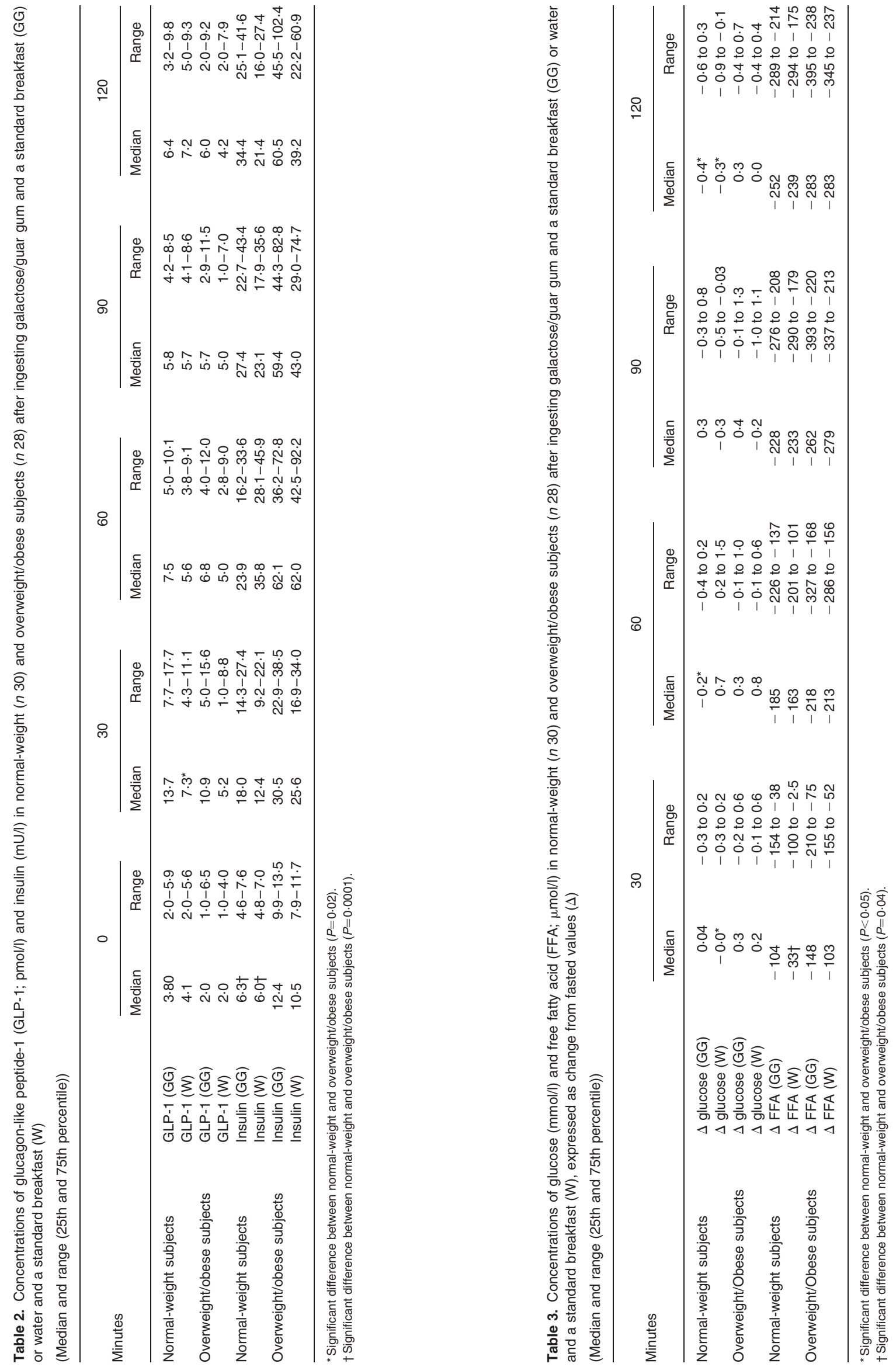


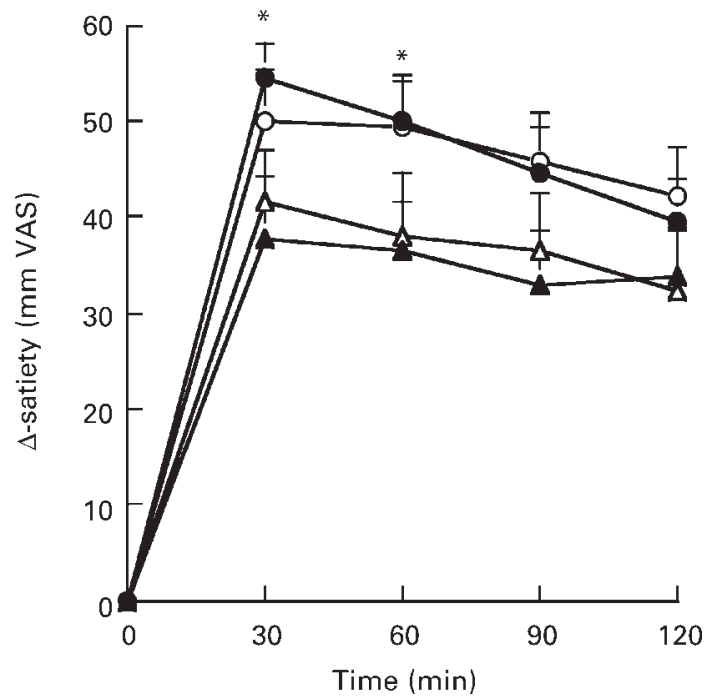

Fig. 6. $\Delta$-satiety (mm VAS) in normal weight $(\bigcirc, \bullet)$ and obese $(\triangle, \mathbf{\Delta})$ subjects after ingesting galactose/guar gum and a standard breakfast (GG; $\bullet, \mathbf{\Lambda}$ ) or water and a standard breakfast $(\mathrm{W} ; O, \triangle)$. * Significantly different from obese subjects in the GG condition $(P<0.05)$.

feelings of satiety was significantly higher in normal-weight subjects at $30 \mathrm{~min}\left(\mathrm{~F}_{1,53}=5 \cdot 28 ; P=0.02\right)$ and $60 \mathrm{~min}\left(\mathrm{~F}_{1,52}=4 \cdot 21\right.$; $P=0.04)$ compared with the overweight/obese group (Fig. 6).

\section{Discussion}

The results of the current study show a significant difference in postprandial GLP-1 stimulation in normal-weight subjects compared with overweight/obese subjects after ingestion of the $\mathrm{W}$ meal. Ingestion of the GG meal seems to outweigh this difference. Galactose in combination with guar gum has been shown to sufficiently stimulate GLP-1 release in normal-weight subjects. The AUC for GLP-1 release stimulated by galactose/guar gum was similar to the AUC for stimulation by glucose/guar gum (Hughes et al. 2004). The question remained whether this could be seen in overweight/obese subjects as well.

The sensitivity of a GLP-1 response seems slightly higher in the normal-weight than the overweight/obese subjects, as shown by the difference in the GLP-1 response to W. However, baseline GLP-1 appeared not to be different between the subjects, and nor did the increase in GLP-1 release due to a stronger trigger such as GG. With the GG load, the effect of the additional energy intake may also have stimulated GLP-1 release in the overweight/obese subjects. It has to be taken into consideration that a decreased L-cell stimulation in overweight/obese individuals, due to a relatively lower kilojoule stimulation per kilogram body weight, might possibly contribute to the difference in GLP-1 release in normal-weight and overweight/obese subjects. However, a between- as well as a within-subject design has been applied in the present study. The difference between overweight/obese and normal-weight subjects, when subtracting GLP-1 release after W from GLP-1 release after GG, was not significant, suggesting a lower sensitivity rather than a decreased L-cell stimulation.

The present findings are different from observations by Ranganath et al. (1996, 1999) and Verdich et al. (2001), who reported a pronounced attenuation of postprandial GLP-1 response in obese subjects. In those studies, obese subjects with a higher BMI $\left(38-40 \mathrm{~kg} / \mathrm{m}^{2}\right)$ were assessed, in whom the GLP-1 release may be lower than in our obese subjects with a BMI of $30 \mathrm{~kg} / \mathrm{m}^{2}$. It was suggested before that GLP-1 response to a nutrient trigger normalises gradually with weight loss (Verdich et al. 2001). According to the WHO classification, the subjects investigated in the present study can be classified as overweight/obese class I, compared with obese class II subjects in the other studies.

GLP-1 has been shown to reduce energy intake, enhance sensations of fullness and decrease feelings of hunger in lean (Flint et al. 1998) as well as in obese (Näslund et al. 1999; Flint et al. 2001) subjects. Therefore, one would expect that higher GLP-1 concentrations in the GG condition than in the W condition in both groups would be mirrored in appetite ratings being related to GLP-1 concentration.

This is only the case in normal-weight subjects, in whom we found a weak relationship between satiety and GLP-1 release. Also, the almost similar GLP-1 concentrations in normal-weight and obese subjects in the GG condition would be expected to be reflected in similar appetite ratings. However, despite no difference in GLP-1 stimulation with GG between the obese and the normal-weight subjects, perceived satiety was increased only in those of normal weight, and not in those who were obese. This could be an example of inappropriate feedback in a situation of energy imbalance (French \& Cecil, 2001).

Two groups with significantly different body weight status were investigated in the present study. Leptin is considered to be an important adiposity signal and is secreted in direct proportion to the amount of fat stored in individual adipocytes (Woods et al. 2000). Leptin has been shown to stimulate GLP-1 release, and it has been suggested that leptin resistance may account for decreased GLP-1 concentrations in obese humans (Anini \& Brubaker, 2003). Leptin was not measured in this experiment, yet the lack of difference in GLP-1 release after GG between overweight/obese and normal-weight subjects suggests that the subjects are probably not leptin resistant. The difference in GLP-1 release between the groups after W may, however, indicate the start of the development of leptin resistance. A stronger trigger, such as GG, still seems to be able to compensate for this.

Insulin release parallels glucose release. Higher plasma insulin concentrations in both groups at 90 and $120 \mathrm{~min}$ in the GG compared with the $\mathrm{W}$ condition are probably due to a reduced rate of glucose absorption, which will lead to a prolonged influence on insulin concentration (van Nieuwenhoven et al. 2001).

As has been shown before (Lavin \& Read, 1995), the addition of guar gum decreased insulin and glucose release compared with the condition without guar gum in both the normal-weight and the overweight/obese group. Insulin is an important adiposity signal (Woods et al. 2000) and has been reported to produce anorexic responses, including reduced food intake and body weight (Baskin et al. 1999; Air et al. 2002). Higher satiety scores in the normal-weight group correspond to a lower insulin release compared with the overweight/obese group. In the present study, no differences between the GG and W conditions have been observed that would support the idea of increased insulin concentrations contributing to increased satiety in the short term. However, unlike other hormones, such as cholecystokinin, with which hypophagia is of rapid onset and lasts for only a few minutes after administration, the hypophagia following insulin develops much more slowly and has been shown to last hours 
or days (Woods, 2004), in line with the view of insulin as a longterm adiposity and satiety signal (Havel, 2001).

In conclusion, obese subjects seem to have a slightly lower sensitivity to GLP-1 release in response to a standard nutrient challenge, such as a standard breakfast, when compared with normal-weight subjects. The sensitivity can be improved to a level comparable to that of normal-weight subjects by the addition of a stronger challenge, for example a galactose/guar gum nutrient load. However, since the improvement is not reflected in subjective sensations of satiety, it seems likely that, in obese subjects, a disturbance in appropriate perception of the feedback rather than primarily a disturbance in physiological feedback may contribute to obesity.

\section{References}

Air EL, Benoit SC, Clegg DJ, Seeley RJ \& Woods SC (2002) Insulin and leptin combine additively to reduce food intake and body weight in rats. Endocrinology 143, 2449-2452.

Anini Y \& Brubaker PL (2003) Role of leptin in the regulation of glucagon-like peptide-1 secretion. Diabetes 52, 252-259.

Baskin DG, Figlewicz Lattemann D, Seeley RJ, Woods SC, Porte D Jr \& Schwartz MW (1999) Insulin and leptin: dual adiposity signals to the brain for the regulation of food intake and body weight. Brain Res 848, 114-123.

Blundell JE, Lawton CL \& Hill AJ (1993) Mechanisms of appetite control and their abnormalities in obese patients. Horm Res 39, 72-76.

Bortz J (1993) Statistik fuer Sozialwissenschaftler, 3rd, Berlin: Springer.

Elliott RM, Morgan LM, Tredger JA, Deacon S, Wright J \& Marks V (1993) Glucagon-like peptide-1 (7-36)amide and glucose-dependent insulinotropic polypeptide secretion in response to nutrient ingestion in man: acute post-prandial and 24-h secretion patterns. $J$ Endocrinol 138, 159-166.

Flint A, Raben A, Astrup A \& Holst JJ (1998) Glucagon-like peptide 1 promotes satiety and suppresses energy intake in humans. J Clin Invest 101, 515-520.

Flint A, Raben A, Ersbøll AK, Holst JJ \& Astrup A (2001) The effect of physiological levels of glucagon-like peptide-1 on appetite, gastric emptying, energy and substrate metabolism in obesity. Int $J$ Obes Relat Metab Disord 25, 781-792.

French SJ \& Cecil JE (2001) Oral, gastric and intestinal influences on human feeding. Physiol Behav 74, 729-734.

Fukase N, Igarashi M, Takahashi H, Manaka H, Yamatani K, Daimon M, Tominaga M \& Sasaki H (1993) Hypersecretion of truncated glucagon-like peptide-1 and gastric inhibitory polypeptide in obese patients. Diabet Med 10, 44-49.

Gee JM, Lee-Finglas W, Wortley GW \& Johnson IT (1996) Fermentable carbohydrates elevate plasma enteroglucagon but high viscosity is also necessary to stimulate small bowel mucosal cell proliferation in rats. J Nutr 126, 373-379.

Gutzwiller JP, Drewe J, Göke B, Schmidt H, Rohrer B, Lareida J \& Beglinger C (1999) Glucagon-like peptide-1 promotes satiety and reduces food intake in patients with diabetes mellitus type 2. Am J Physiol 276, R1541-R1544.

Havel PJ (2001) Peripheral signals conveying metabolic information to the brain: short-term and long-term regulation of food intake and energy homeostasis. Exp Biol Med (Maywood) 226, 963-977.

Hughes TE, Westerterp-Plantenga MS \& Adam TCM (2004) Nutritional compositions comprising a non-glucose carbohydrate or pectine and soluble fiber. In WO 2004/022074 A1

Juntunen KS, Niskanen LK, Liukkonen KH, Poutanen KS, Holst JJ \& Mykkanen HM (2002) Postprandial glucose, insulin, and incretin responses to grain products in healthy subjects. Am J Clin Nutr $\mathbf{7 5}$, $254-262$.
Kreymann B, Williams G, Ghatei MA \& Bloom SR (1987) Glucagon-like peptide-1 7-36: a physiological incretin in man. Lancet 2, 1300-1304.

Lavin JH \& Read NW (1995) The effect on hunger and satiety of slowing the absorption of glucose: relationship with gastric emptying and postprandial blood glucose and insulin responses. Appetite 25, 89-96.

Massimino SP, McBurney MI, Field CJ, Thomson AB, Keelan M, Hayek MG \& Sunvold GD (1998) Fermentable dietary fiber increases GLP-1 secretion and improves glucose homeostasis despite increased intestinal glucose transport capacity in healthy dogs. J Nutr 128, $1786-1793$.

Morley JE (1990) Appetite regulation by gut peptides. Annu Rev Nutr 10, 383-395.

Näslund E, Barkeling B, King N, Gutniak M, Blundell JE, Holst JJ, Rössner S \& Hellström PM (1999) Energy intake and appetite are suppressed by glucagon-like peptide-1 (GLP-1) in obese men. Int $J$ Obes Relat Metab Disord 23, 304-311.

Näslund E, Gutniak M, Skogar S, Rössner S \& Hellström PM (1998) Glucagon-like peptide 1 increases the period of postprandial satiety and slows gastric emptying in obese men. Am J Clin Nutr 68, 525-530.

Nathan DM, Schreiber E, Fogel H, Mojsov S \& Habener JF (1992) Insulinotropic action of glucagonlike peptide-I-(7-37) in diabetic and nondiabetic subjects. Diabetes Care 15, 270-276.

Pasman WJ, Saris WH, Wauters MA \& Westerterp-Plantenga MS (1997) Effect of one week of fibre supplementation on hunger and satiety ratings and energy intake. Appetite 29, 77-87.

Pittler MH \& Ernst E (2001) Guar gum for body weight reduction: meta-analysis of randomized trials. Am J Med 110, 724-730.

Ranganath L, Norris F, Morgan L, Wright J \& Marks V (1999) Inhibition of carbohydrate-mediated glucagon-like peptide-1 (7-36)amide secretion by circulating non-esterified fatty acids. Clin Sci (Lond) $\mathbf{9 6}$, $335-342$.

Ranganath LR, Beety JM, Morgan LM, Wright JW, Howland R \& Marks V (1996) Attenuated GLP-1 secretion in obesity: cause or consequence? Gut 38, 916-919.

Schoeller DA, van Santen E, Peterson DW, Dietz W, Jaspan J \& Klein PD (1980) Total body water measurement in humans with ${ }^{18} \mathrm{O}$ and ${ }^{2} \mathrm{H}$ labeled water. Am J Clin Nutr 33, 2686-2693.

Thorens B, Porret A, Buhler L, Deng SP, Morel P \& Widmann C (1993) Cloning and functional expression of the human islet GLP-1 receptor. Demonstration that exendin-4 is an agonist and exendin-(9-39) an antagonist of the receptor. Diabetes 42, 1678-1682.

Tillil H, Shapiro ET, Miller MA, Karrison T, Frank BH, Galloway JA, Rubenstein AH \& Polonsky KS (1988) Dose-dependent effects of oral and intravenous glucose on insulin secretion and clearance in normal humans. Am J Physiol 254, E349-E357.

van Marken Lichtenbelt WD, Westerterp KR \& Wouters L (1994) Deuterium dilution as a method for determining total body water: effect of test protocol and sampling time. Br J Nutr 72, 491-497.

van Nieuwenhoven MA, Kovacs EM, Brummer RJ, Westerterp-Plantenga MS \& Brouns F (2001) The effect of different dosages of guar gum on gastric emptying and small intestinal transit of a consumed semisolid meal. J Am Coll Nutr 20, 87-91.

Verdich C, Toubro S, Buemann B, Lysgard-Madsen J, Holst JJ \& Astrup A (2001) The role of postprandial releases of insulin and incretin hormones in meal-induced satiety - effect of obesity and weight reduction. Int J Obes Relat Metab Disord 25, 1206-1214.

World Health Organization (1998) Obesity: Preventing and Managing the Global Epidemic. WHO/NUT/NCD/98.1. Geneva: WHO.

Woods SC (2004) Lessons in the interactions of hormones and ingestive behavior. Physiol Behav 82, 187-190.

Woods SC, Schwartz MW, Baskin DG \& Seeley RJ (2000) Food intake and the regulation of body weight. Annu Rev Psychol 51, 255-277. 